\title{
YO O LAS TRAMPAS DE LA BIOGRAFÍA
}

\author{
Werner Mackenbach
}

\begin{abstract}
RESUMEN
El ensayo propone una nueva lectura de la obra de Yolanda Oreamuno que supere su canonización basada en los enfoques biografistas y contenidistas así como la supuesta identidad entre obra y vida, que hasta ahora han dominado en la crítica. Una lectura que cumpla con este requisito -y que se realiza en este articulo- podrá ser una de la novela La ruta de su evasión desde la geografía literaria, es decir, una lectura que en contraposición a la clasificación de Manuel Picado Gómez de la obra como novela de personaje y no novela de espacio, se ocupa exactamente del espacio de y en esta novela en cuatro dimensiones: la representación de espacios físicos, la semantización de los espacios físicos, el texto como espacio y el espacio literario entre autora, obra y lectores.

Palabras clave: literatura costarricense, Yolanda Oreamuno, biografismo, literatura femenina, geografía literaria, novela de espacio
\end{abstract}

\begin{abstract}
This essay proposes a new lecture of Yolanda Oreamuno's work that may overcome its canonization based on "biographist" and "contentist" approaches and the supposed identity of work and life, which have dominated in the critic up to the moment. One possible lecture which meets these requisites -and which is being realized in this article- could be one of his novel La ruta de su evasión from the perspective of literary geography, that means, a lecture which in contrast to Manuel Picado Gómez's classification of the text as a novel of personage and not a novel of space, analyzes the space of and in this novel in four dimensions: the representation of physical spaces, the signifying of physical spaces, the text as space and the literary space between the author, the work and the readers.
\end{abstract}

Key words: Costa Rican literature, Yolanda Oreamuno, biographism, women literature, literary geography, novel of space

\footnotetext{
Werner Mackenbach. Universidad de Potsdam, Alemania. Universidad de Costa Rica Correo electrónico: wmackenbach@amnet.co.cr
}

Recepción: 17- 9- 2008

Aceptación: 23- 10- 2008 
"En Costa Rica es necesario morirse para recoger el reconocimiento póstumo de este pueblo desdeñoso y pasivo" - parece que con estas palabras Yolanda Oreamuno anticipó proféticamente en su ensayo "El último Max Jiménez ante la indiferencia nacional", publicado en el Repertorio Americano en 1939, su propio destino como autora1. De hecho, durante muchos años esta escritora ha sido una herida abierta en la historiografía literaria y cultural de Costa Rica y Centroamérica, así como la gran ausente en la literatura hispanoamericana; situación que apenas hace algunos años ha ido cambiando paulatinamente. En un artículo publicado en vísperas del cincuenta aniversario de su fallecimiento (ocurrido el 8 de julio de 1956), el escritor costarricense Alfonso Chase se refirió, de manera abiertamente polémica, a algunas de las fisuras apenas o mal cicatrizadas de esta herida:

\footnotetext{
Algunos y algunas intentaron conocerla donde sólo había sombras. Otros y otras, rebuscaron en sus psicologías, no en la de ella, para oreamunarse, en donde sólo había jirones de mediocridad y resentimiento. O admiración basada en la identificación, postiza, de un destino único, singular y propio, para darle forma al mundo que le rodeaba, el interno y el colectivo (Chase 2006).
}

\section{Una herida abierta}

De hecho, hasta a inicios de los años 60 cuando se editaron una selección de sus trabajos publicados en revistas (ensayos, cuentos, cartas, etc.) y algunos fragmentos de su novela La ruta de su evasión en el tomo A lo largo del corto camino (selección de Lilia Ramos y otros) en la Editorial Costa Rica y hasta la publicación de la primera edición costarricense de la novela mencionada en 1970 por EDUCA en San José , la obra de Yolanda Oreamuno quedó casi desapercibida en los estudios literarios a nivel nacional e internacional -situación que en parte se explica por la publicación dispersa de muchos de sus textos periodísticos, ensayísticos y narrativos durante su vida y la no publicación de la mayor parte de su obra novelística ${ }^{3}$. En su artículo ya citado, Alfonso Chase hace referencia a otros factores que pueden explicar el "manto tendido sobre el valor de su obra literaria", es decir, "una combinación de desprecio, e ignorancia" sobre sus "extraños y valiosos cuentos" y sus textos periodísticos, que "algunos juzgaban demasiado duros para un ambiente aldeano y escurridizo" (Chase 2006), a lo que podríamos añadir las trabas en la recepción de una novela igualmente "dura" y de difícil lectura para un público lector que estaba acostumbrado al consumo de literatura regionalista y costumbrista, así como -pero ya en un grado menor- de realismo social.

Sin embargo, ya a partir de los años 60 (con la publicación de A lo largo del corto camino) y aún más de finales de los 60/inicios de los 70 no han faltado los intentos de rescatar esta obra4; una situación algo paradójica que, en el año 1979, llevó a Manuel Picado Gómez a la conclusión de que "aún escritores como Carlos Luis Fallas, Fabián Dobles o Joaquín Gutiérrez, no tienen, al menos en Costa Rica, ningún estudio de este tipo, no obstante su amplia publicación en lengua española y las múltiples traducciones con que cuentan" (Picado Gómez 1979: 31), haciendo referencia al libro de Victoria Urbano ${ }^{5}$. De hecho, comenzando con Una escritora costarricense: Yolanda Oreamuno. Ensayo crítico de Urbano, publicado en 1968 en Madrid, y la tesis de licenciatura La ruta de su evasión de Yolanda Oreamuno. Deslinde metodológico y contribución al estudio de la literatura costarricense, de Manuel Picado Gómez en 1973 (publicada en forma de libro en 1979), Yolanda Oreamuno y su obra (especialmente su única novela publicada, La ruta de su evasión) han sido objeto de estudio de numerosos libros, tesis y ensayos, entre estos los trabajos de Carmen Naranjo 
Coto (1971), Haydeé Garro Jiménez (1977), María Eugenia Arce Arce (1980), Rima de Vallbona (1975, 1995, 2006), Yvonne Robles Mohs (1988) y Emilia Macaya (1997), así como de obras panorámicas de la literatura costarricense, por ejemplo en Abelardo Bonilla (1961), Alfonso Ulloa Zamora (1962), Alfonso Chase (1975), Flora Ovares et alii (1993) y Margarita Rojas/ Flora Ovares (1995), para solamente mencionar las contribuciones más importantes, mientras que los estudios a nivel internacional solamente han comenzado a ocuparse otra vez de la escritora costarricense muy recientemente, especialmente en el marco de los gender studies en la literatura (ver por ejemplo Barbas-Rhoden 2003). Es indudable que, hasta hoy en día, estos estudios han contribuido de manera determinante a la construcción e incluso canonización de algunas facetas de la imagen de Yolanda Oreamuno y su obra.

La primera de estas facetas la llamaría un pronunciado "fundacionalismo". En su artículo "Un nuevo modo de narrar: La ruta de su evasión de Yolanda Oreamuno", publicado en Káñina: Revista de Artes y Letras de la Universidad de Costa Rica en 1988, Yvonne Robles Mohs le asignó a Yolanda Oreamuno -junto con Fabián Dobles, Carlos Luis Fallas y Joaquín Gutiérrez- el papel de inauguradora de "la narrativa nacional contemporánea con la búsqueda de nuevos horizontes temáticos, espacios narrativos y procedimientos constructivos" (Robles Mohs 1988: 49). Este criterio de cierta manera "generacionalista" es compartido por muchos de los estudiosos literarios anteriormente mencionados, los cuales destacan que mientras Dobles, Fallas y Gutiérrez rompieron con la tradición costumbrista y regionalista por su descubrimiento de una otra Costa Rica social y política (sea a través de la temática social en general, sea a través de la inclusión del Caribe en la literatura costarricense), Yolanda Oreamuno lo hizo a través de su inmersión en los mundos interiores hasta ese momento desconocidos, descubriendo así la otra Costa Rica en la psique de sus personajes (ver Urbano 1968: 53-5; Ovares et alii 1993: 264; Rojas/ Ovares 1995: 140-2).

Esta ubicación de Yolanda Oreamuno como parte integral y especialmente significativa de la así llamada "generación del cuarenta" (Rojas/Ovares 1995: 127) -fundadora de la nueva literatura costarricense- es apoyada por los estudios que más se ocupan de los aspectos literarios formales de su obra, aunque de manera contradictoria. Manuel Picado Gómez critica en las conclusiones de su análisis sobre La ruta de su evasión, que la novela se caracteriza por la sumisión de la narración a las convicciones de la autora. De esta manera, según el criterio de Picado, Yolanda Oreamuno, al igual que los otros representantes de la "generación del cuarenta", "entiende lo narrado como sometido a sus premisas y convierte la historia en medio que hace posible una mostración cuyos alcances tienen los límites y contradicciones del estrago ambiguo del narrador" (Picado Gómez 1979: 98), lo cual le hace definir este rasgo como una tendencia estructural común en la producción narrativa de esa generación, que ve constituida en la oposición "novelas de espacio (Dobles, Fallas, Gutiérrez)" y "novelas de personajes (Oreamuno)" (Picado Gómez 1979: 99; ver también Ovares/ Rojas/ Santander/ Carballo 1993: 267- 268). En contraposición, Margarita Rojas y Flora Ovares destacan el momento de ruptura de la novela con la tendencia artística dominante de su época, es decir, la concepción de la obra literaria como reproducción y denuncia de la realidad social:

\footnotetext{
Por el contrario, esta novela cuestiona la noción de la obra literaria como reflejo de un orden externo, más bien, propone su autonomía: el texto posee leyes y mecanismos particulares que le confieren realidad. Algunos aspectos que ejemplifican esa ruptura antirrealista son:

•el orden no lineal de la narración,

-el tratamiento del espacio y

•la importancia de la palabra (1995: 140).
} 
No obstante, las dos estudiosas mantienen igualmente la ubicación de la novela de Oreamuno en el ámbito de una literatura de "preocupación por el aspecto social propia de su generación" (Rojas/ Ovares 1995: 141).

\section{Un sesgo biografista}

Muchos de los estudios mencionados que se dedican al análisis de las formas y estructuras literarias de la novela de Oreamuno se han ocupado ampliamente del estudio de estos elementos innovadores en el contexto de la literatura costarricense de su época (especialmente Picado Gómez 1979: 31-101; Robles Mohs 1988; Macaya 1997: 135-182; y también Urbano 1968: 160-185; Vallbona 2006: 59- 73). Sin embargo, en este análisis predomina, por un lado, un enfoque "personalista", es decir, en su mayoría los estudios se limitan a analizar el papel estructurante y dominante de los personajes principales de la novela y sus relaciones -"los protagonistas son: Teresa, Gabriel y Aurora" (Picado Gómez 1979: 36) -obviamente motivado por el hecho de que en contraposición a la tradición novelística dominante de la época "el desarrollo de la fábula no está [...] regido por el acontecimiento” (Picado Gómez 1979: 35), es decir, la novela carece casi por completo de largos pasajes de descripción narrativa (Ovares et alii 1993: 265). Junto a este enfoque se halla un acercamiento“temático" a la novela, es decir, los análisis privilegian identificar y comentar los principales temas tratados en la novela y su relación con las otras publicaciones (periodísticas y ensayísticas) de la autora, otorgando especial énfasis a la problemática de las relaciones hombre-mujer y de la sexualidad ${ }^{6}$. Por el otro lado, prevalece una especie de "comparatismo", un enfoque comparativo que, basándose en el recurso dominante a diferentes formas del monólogo en la novela y las afirmaciones de Yolanda Oreamuno misma sobre sus lecturas de algunos "maestros" de la novela contemporánea europea y estadounidense como Thomas Mann, William Faulkner y especialmente Marcel Proust, clasifica la novela de Oreamuno como una especie de adaptación tropical de la más reciente modernidad literaria europea de su tiempo (ver especialmente el capítulo "Influencias" en Urbano 1968: 176-85, 160-6; Vallbona 2006: 25- 7)7.

Desde muy temprano estos enfoques de análisis han estado acompañados por una lectura feminista, o mejor dicho por la recepción de la novela de Yolanda Oreamuno como literatura femenina e incluso feminista avant la lettre (ver por ejemplo Ulloa Zamora 1962). En su tesis de licenciatura presentada en la Universidad de Costa Rica en 1980, "Inner and Outer World in To the Lighthouse and La ruta de su evasión", Marta Eugenia Arce Arce sostuvo:

\footnotetext{
As critics, essayists and novelists, Woolf and Oreamuno belong to the modern generation of women writers. They represent the new age of feminine consciousness and incarnate this struggle by women to reach a world of their own, to develop their creative powers and assert themselves as independent spirits. These two women writers stand for a feminist position. They are in the vanguard of the true feminist movement (Arce 1980: 12).
}

Emilia Macaya habla en su libro Espíritu en carne altiva, que se dedica por completo al análisis de la obra de Yolanda Oreamuno en el contexto de los gender studies de los años 90, incluso de dos momentos "desde la perspectiva del aporte femenino a la escritura narrativa de nuestro país [...]: antes y después de Yolanda Oreamuno" (Macaya 1997: 81; ver también Cortés 1996: 28-9), relegando así la obra de autoras como Carmen Lyra, Emilia Prieto y Luisa González a un segundo plano. 
Finalmente hay que señalar que estos diferentes y diversos enfoques se mezclan en los mencionados estudios sirviéndose de otro elemento como hilo unificador: la identidad entre obra y vida. Ya en el estudio de Victoria Urbano, que ha jugado un papel de guía para otros que le han seguido, el entretejido inextricable entre la biografía y la obra, entre realidad y ficción, está presente como leitmotiv y punto de partida principal del análisis de la producción literaria de Yolanda Oreamuno. Según Victoria Urbano no encontramos solamente en su obra "a la mujer de ideas y convicciones propias y a la escritora que supo exponerlas con valentía e inteligencia" (Urbano 1968: 20). La "influencia personal sobre unos entes de ficción” en la obra de Yolanda Oreamuno no solamente "alcanza un relieve mucho mayor que en la obra de otros escritores" (Urbano 1968: 47), más bien "el YO suyo fue al mismo tiempo el personaje central de su obra" (Urbano 1968: 65). Para Urbano esto vale rotundamente para sus artículos, páginas, cuentos y narraciones de lo que ella llama el grupo "subjetivo" de la obra de Yolanda Oreamuno, que se puede resumir bajo el tema "Yo y su circunstancia" (Urbano 1968: 62), pero también predomina en sus obras narrativas más importantes, el cuento "Valle alto" y la novela La ruta de su evasión: "en esas obras, también la autora continúa siendo siempre y perennemente, de principio a fin, el personaje central de un mismo tema: su vida y su obra" (Urbano 1968: 64). Marta Eugenia Arce Arce repite y agudiza este argumento incluso doce años después:

\footnotetext{
Virginia Woolf and Yolanda Oreamuno, like most writers, communicate or reveal their own personal experience of life. However, I believe that this relationship between the author and his work is most significant in these two writers, indeed, their interests, feelings, and the circumstances of their lives contribute greatly to their artistic genius (Arce Arce 1980: 6).
}

También Rima de Vallbona, que se vale de la división de la obra de Yolanda Oreamuno en "géneros de carácter objetivo" y "su obra subjetiva" propuesta por Victoria Urbano, consigna que "no hay una página de Yolanda Oreamuno en que no esté ella presente" (Vallbona 2006: $11,13,23-24,27)$.

Me parece pertinente señalar por lo menos dos procedimientos teórico-conceptuales subyacentes a este "biografismo". Por un lado, reclama, especialmente en el análisis de Marta Eugenia Arce, de manera anacrónica la obra de Yolanda Oreamuno para una literatura escrita por mujeres que es expresión inmediata de sus propias experiencias de vida, una literatura de "autotestimonio", construyendo así una relación inseparable entre sexo (biológico), género, vida de la autora y creación literaria, una posición muy dominante en los discursos feministas de los años 70 y 80 (posición que, por lo menos, parcialmente es superada en el estudio de Emilia Macaya). Por otro lado, recurre al concepto de "genio" literario, aceptando así una construcción de la autora Yolanda Oreamuno misma, que separa la serie vida artística/obra literaria de la vida común y civil, repitiendo así un procedimiento muy propio del incipiente campo literario de finales del siglo XX e inicios del siglo XX, especialmente en el Modernismo ${ }^{8}$. Finalmente, este procedimiento ha contribuido a otro leitmotiv en la percepción y recepción de Yolanda Oreamuno y su obra por parte de la crítica internacional y especialmente de la costarricense: la estilizada relación entre su belleza física y la belleza de su obra literaria en contraposición a la fealdad de su destino en la vida familiar y civil, como ya lo sostuvo Victoria Urbano: "Es increíble que una mujer dotada tan excepcionalmente por la naturaleza fuese, por otra parte, tan injustamente tratada por el destino, por ese destino amargo que la hizo sufrir sin misericordia" (Urbano 1968: 21). 
Este argumento no muy lógico - de ninguna manera la belleza física me parece ser una garantía de una vida social llena de belleza, algo como un paliativo contra las injusticias mundanas- de hecho se ha convertido en un elemento central del "mito" Yolanda Oreamuno del que habla Rima de Vallbona (2006: 6) y al que la crítica literaria misma ha contribuido significativamente (Cortés 1996: 28).

\section{Una lectura alternativa}

Es innegable que los estudios mencionados y sus enfoques aquí brevemente descritos han contribuido a rescatar la obra de Yolanda Oreamuno del olvido y de la negación. Sin embargo, al mismo tiempo han redundado también en cierta canonización de su obra y en una vinculación inseparable entre el texto ficcional y la vida real, ignorando lo que Alfonso Chase afirmaba en el artículo ya citado: "El secreto de Yolanda Oreamuno es el haber guardado una distancia sutil entre su mundo personal y la expresión novelística, para tratar de evitar el equívoco de que sólo escribía sobre ella, su mundo, sus sentimientos, sus desgracias" (Chase 2006).

En mi criterio está pendiente emprender nuevas lecturas de su obra que contribuyan a entender mejor este secreto del que habla el escritor costarricense, liberándose de las trampas de la biografía y del biografismo. Una lectura que cumpla con este requisito podría ser una de La ruta de su evasión desde la geografía literaria, es decir, una lectura que, en contraposición a la clasificación de Manuel Picado Gómez de la obra como novela de personaje y no novela de espacio, se ocupe exactamente del espacio de y en esta novela en cuatro dimensiones: la representación de espacios físicos, la semantización de los espacios físicos, el texto como espacio y el espacio literario entre autora, obra y lectores ${ }^{9}$.

En relación con la primera dimensión (la representación de espacios físicos) hay que destacar y reiterar que la novela carece de largas descripciones narrativas de espacios físicos extratextuales. Estas alusiones directas en la estructura de la novela se reducen a pocas líneas que ubican la acción, mejor dicho, los recuerdos narrados (principalmente en monólogos, diálogos y diálogos en el monólogo) en un entorno físico. Sin embargo, en los largos pasajes monologados y dialogados abundan las referencias y representaciones de espacios extratextuales, como la ciudad, la casa, el prostíbulo, la universidad, la morgue "privada", el cuerpo y el espacio interior (la memoria, la conciencia de los personajes). Este hecho ya de por sí es un aspecto que rompe de manera significativa con las tradiciones de las literaturas costarricense y centroamericanas dominantes en el momento de escritura y publicación de La ruta de su evasión (sea del costumbrismo y regionalismo, sea del incipiente realismo o neorrealismo social, que se dedicaban casi exclusivamente a la representación de espacios rurales, sin penetrar ni adentrarse en los espacios interiores, íntimos de sus personajes) (Rojas/ Ovares 1995: 127, 140-1; Robles Mohs 1988: 50; Urbano 1968: 55). Debemos hacer especial énfasis en que estas representaciones de los espacios físicos se dan a través del espacio interior de los personajes y no en el relato "directo" del narrador. Emilia Macaya señala la presencia de algunas incursiones literarias anteriores en este espacio interior, por ejemplo en El infierno verde (1935) de José María Cañas y Manglar (1947) de Joaquín Gutiérrez (Macaya 1997: 148); sin embargo, la construcción de la estructura de una obra literaria casi exclusivamente alrededor de dicho espacio interior no cuenta con antecedentes en esa época: "el gesto radical de esta novela, al concentrarse totalmente en el mundo interior de los personajes, no tiene 
antecedentes dentro de la literatura del país. Así, el campo de lo decible se ensancha con esta nueva dimensión" (Ovares et alii 1993: 264) ${ }^{10}$.

Este aspecto adquiere aún más relevancia y se vuelve más evidente si lo relacionamos con el proceso de semantización de estos espacios físicos, que los convierte en metáforas de la autopercepción, el estado de ánimo y la conciencia de los personajes de la novela. Hay un constante procedimiento de semantización espacial en la novela, es decir, de uso de metáforas espaciales para describir y expresar cosas o sucesos no espaciales, sin que exista una correspondencia directa entre el espacio extraliterario percibido y la semantización espacial. La ciudad, la casa, el burdel y el cuerpo se convierten en metáforas de la violación, la enajenación, la humillación, la no-comunicación, el aislamiento, la no-realización de los individuos. Es especialmente notable como el cronotopos literario dominante en la tradición costarricense de ese período ${ }^{11}$ - la casa (paterna) como metáfora, hasta símbolo, de la identidad, unidad y "naturalidad" del ser costarricense basado en la familia patriarcal y rural- es deconstruido por su semantización como lugar de mayor no-identidad de los personajes que tienen que vivir en ella ${ }^{12}$. Algo similar sucede con la semantización "genérica" (en el sentido de gender) del cuerpo, espacio de identidad por excelencia: el espacio interior es un espacio casi exclusivamente femenino, el espacio exterior es masculino; Macaya, dedica toda la última parte de su estudio a este aspecto (1997: 159-82). Teresa y Gabriel, como personaje masculino más "feminizado" de la novela, sólo llegan a re-encontrarse en un proceso de separación de su cuerpo -el espacio exterior- (la primera en un largo proceso de agonía, mientras el segundo en uno corto de suicidio) y en el adentramiento precisamente en su espacio interior, la memoria, el recuerdo, los deseos suprimidos. El único personaje que escapa a esta semantización "genérica" es Esteban, cuyo cuerpo de hombre ya no es capaz de cumplir con los requisitos masculinos debido a su mutilación.

A esta semantización espacial compleja corresponde una estructura compleja del espacio textual de la novela, que igualmente rompe con los patrones hasta ese momento canonizados en la literatura costarricense. Con razón los estudios de la novela citados en el presente ensayo han hecho hincapié en las rupturas temporales, es decir, de la linealidad cronológica del relato, en las intervenciones metatextuales de la autora y la dominante narración monologada. Con estos elementos, a los que podríamos añadir otros como la semantización espacial de lugares intratextuales, en el primer y el último capítulo de la novela y en los momentos "claves" de los monólogos interiores de Teresa (Urbano 1968: 160-6), la novela se convierte en un espacio "dinámico" (Bronfen 1986: 317, 328, 330-1), cuyo sentido tiene que ser construido por la actividad del lector.

Muy relacionada con este aspecto está, entonces, la recepción de la obra de Yolanda Oreamuno, es decir, el análisis del espacio literario que es constituido por la relación entre autora, texto y lectores. Me parece obvio que la mencionada estructura compleja de la novela en el momento de su publicación impidió o, por lo menos, dificultó esta construcción de sentido por parte de un público lector que estaba acostumbrado a la lectura de obras de índole regionalista y costumbrista -a lo mejor también de realismo social-, es decir, de textos narrados linealmente y basados en la metaforización de la casa familiar costarricense a la que hice alusión arriba. En parte, también esto puede explicar la lectura predominante de la crítica literaria que, aunque ha reconocido la estructura compleja basada en técnicas avanzadas de la modernidad literaria de su época presentes en la totalidad de la novela, continúa haciendo una lectura de la novela como si se tratara de la vida de Yolanda Oreamuno. 


\section{Una obra radical}

Sí, es tiempo para investigar más a fondo la "distancia sutil entre su mundo personal y la expresión novelística" y "evitar el equívoco de que sólo escribía sobre ella, su mundo, sus sentimientos, sus desgracias", como lo reclamó Alfonso Chase en su ensayo citado. Una tal pesquisa, para la cual apenas he esbozado algunas posibles líneas a seguir en este ensayo nos llevará -de esto estoy convencido- a entender mejor la extraordinaria importancia estética y política de la obra de Yolanda Oreamuno y, en especial, de su novela La ruta de su evasión, dentro del desarrollo cultural y político de Costa Rica, también en comparación con otras obras sobresalientes en ese proceso. Esta obra está, como he intentado mostrar, llena de rupturas y continuidades; pero es al mismo tiempo la obra más atrevida y radical de su tiempo en el contexto costarricense, en sentido estético y político. En un artículo publicado junto con Valeria Grinberg Pla acerca de Mamita Yunai (1941) de Carlos Luis Fallas, escribimos lo siguiente:

\footnotetext{
Hay que resaltar que en la novela de Carlos Luis Fallas -al igual que en los cuentos de Bananos y hombres de Carmen Lyra- se hace visible por primera vez el Caribe costarricense, y por primera vez los afrocostarricenses y los indígenas son convertidos en personajes literarios -lo que efectivamente resulta en notables representaciones literarias de la "otra" Costa Rica [...] (2006: 170),

\begin{abstract}
Sin embargo, [...] es una unidad en función de la lucha de clases, del proyecto blanco-mestizo de nación, que hace abstracción de las particularidades étnicas y culturales y de los intereses específicos de estas partes de la población costarricense, que es -además-insensible a las especificidades de género y borra por tanto la experiencia de las mujeres como tales.

El proyecto blanco-mestizo de construcción de la nación efectivamente revela sus límites, política y estéticamente [...](2006: 173).
\end{abstract}

La novela de Yolanda Oreamuno es aún más radical y al mismo tiempo actual. Cuestiona este proyecto basado en la construcción de una sociedad más justa en el Valle Central, que todavía se valía de los recursos (también literarios) de la armoniosa familia costarricense rural-patriarcal, desde adentro, desde la situación "casera" y familiar que se basa en la supresión y humillación de la otredad costarricense femenina, cuyos residuos han sobrevivido hasta nuestros días (basta pensar en los índices de violencia doméstica de los años recientes). Y lo hace en una forma literaria que, en contraposición a otros textos que entretanto se han transformado en meros documentos literario-históricos, igualmente ha sobrevivido los avatares históricos y nos sigue dando un gran goce estético.

\section{Notas}

1. "El último Max Jiménez ante la indiferencia nacional”. Repertorio Americano, vol. 36, no. 18: $281-283$ (aquí citado de Oreamuno 1961: 38).

2. La primera edición fue publicada en 1950 por el Ministerio de Educación de Guatemala, donde la novela había recibido el "Premio Centroamericano 15 de Setiembre" en 1948 (ver acerca de esta historia de edición Picado Gómez 1979: 31).

3. Ver la reconstrucción de estas obras no publicadas en de Vallbona, 2006: 17-18 y 113-5.

4. Ver la bibliografía en de Vallbona, 2006: 109-111. 
5. Picado Gómez escribe: "A pesar de la escasa difusión editorial de la obra de Yolanda Oreamuno -no pasan de cinco mil los volúmenes publicados- nos hemos encontrado con que su novela ha ofrecido una atracción relativamente fuerte ante los ojos de la 'crítica' nacional y extranjera. Ya se han escrito en torno a la obra una cantidad considerable de artículos y ensayos y es muy significativo el hecho de que su obra total sea incluso poseedora de un estudio de las proporciones del libro de Victoria Urbano" (Picado Gómez 1979: 31).

6. Es notable que los estudios tan diversos de Picado Gómez, Vallbona y Macaya coinciden en este enfoque personalista y temático (ver Picado Gómez 1979: 33-7, 81-97; Macaya 1997: 83-130, 135-82; Vallbona, 2006:61-73, 77-82). Emilia Macaya resalta, apoyándose en el estudio de Ovares et alii (1993), que la novela "se adelanta a su época" (Macaya 1997: 88) por su ocupación con el tema de la violencia doméstica (ver también Ovares et alii 1993: 264; Rojas/ Ovares, 1995: 140).

7. Cabe resaltar el análisis crítico de Picado Gómez hacia las diferentes formas de monólogo existentes en La ruta de su evasión y la relativamente poca importancia del monólogo interior o el libre fluir de la conciencia (Picado Gómez 1979: 32, 73-8; ver también la posición parcialmente contrapuesta de Macaya 1997: 142-57).

8. Victoria Urbano que se refiere de manera afirmativa a este rasgo en la producción de Yolanda Oreamuno cita de una carta publicada en el libro A lo largo del corto camino: "Entregarse al genio, ser cosa suya, tierra de su simiente, olor de su flor, objeto de su actividad, campo para que actúe, es entregarse a la muerte y vivirla minuto a minuto. El genio es allá donde se rompen las medidas, donde tú estás solo, absolutamente solo, y no te sirven las palabras de los otros, ni sus sonrisas, ni siquiera su amor. Es estar cohabitando con la muerte en todos los segundos. Es no poder conjugar con los demás, es dejar de tener familia humana y convertirse en la soledad y la muerte mismas, caminando, moviéndose y tratando vanamente de parecerse a los que representan la humanidad y la compañía. Yo tengo miedo de ser eso y eso quiero y debo ser." (citado en Urbano, 1968: 41-2; confrontése también su posición acerca de la "teoría del genio" de Yolanda Oreamuno: 40-7).

9. $\quad$ En esta propuesta para una relectura de la novela de Yolanda Oreamuno me baso especialmente en tres estudios de científicos alemanes: son los trabajos Literarische Geographie Lateinamerikas. Zur Entwicklung des Raumbewußtseins in der lateinamerikanischen Literatur (2000) de la latinoamericanista Andrea Mahlendorff, Literatur in Bewegung. Raum und Dynamik grenzüberschreitenden Schreibens in Europa und Amerika (2001) del romanista/latinoamericanista Ottmar Ette (publicado en inglés bajo el título Literature on the Move en 2003) y Der literarische Raum (1986) de la anglicista Elisabeth Bronfen, que hasta el momento ha permanecido desapercibido en el contexto de los estudios latinoamericanos. Bronfen propone toda una conceptualización del espacio literario a partir del análisis de la obra novelística de la autora inglesa Dorothy M. Richardson (1882-1957), Pilgrimage (12 vol., 1915-1938), que en la crítica literaria vale como una de las primeras autoras que utilizó la técnica del fluir de la conciencia, aún antes de James Joyce y Virginia Woolf. Recurrir a este estudio en el análisis de la novela de Yolanda Oreamuno me parece aún más justificado tomando en cuenta las relaciones que establece Emilia Macaya (1997: 158-9) entre las obras de las dos autoras (Woolf y Oreamuno).

10. No comparto el argumento de la ausencia del "ambiente nacional" en la novela como lo sostiene Abelardo Bonilla en su Historia de la literatura costarricense (1957: 328) y como lo reiteran Flora Ovares et alii (1993: 264): "Si lo nacional tiende a definirse a partir de un espacio y un tiempo objetivos, exteriores a los sujetos, la novela carece entonces de dimensión nacional [...] La concepción con que se construye un discurso que supone un espacio y un tiempo exteriores es, lógicamente, referencialista. Lo nacional se supone como algo independiente del lenguaje y, por lo tanto, esencial. Por el contrario, la novela de Oreamuno prescinde en buena parte de la realidad exterior al lenguaje y participa así de una concepción más contemporánea de este.” Si lo nacional y lo temporal-espacial no están presentes de manera costumbrista-regionalista o realista/neorrealista, sí lo están de otra manera, como analizado en este ensayo. 
11. Aquí me refiero a Mijail Bajtín quien definó en uno des sus estudios más conocidos (Problemas literarios y estéticos, La Habana: Editorial Arte y Literatura, 1986) el cronotopos como "la intervinculación esencial de las relaciones temporales y espaciales asimiladas artísticamente en la literatura", entendiéndolo como "una fusión de los indicios espaciales y temporales en un todo consciente y concreto" (169).

12. Sin analizar la obra de Yolanda Oreamuno (a la que menciona solamente una vez y de paso en relación con artículos publicados en la revista Repertorio Americano; ver Quesada, 1998: 163), Álvaro Quesada Soto dedica un capítulo entero de su estudio Uno y los otros. Identidad y literatura en Costa Rica 1890-1940 (1998) al análisis de los cambios político-sociales y estético-culturales en Costa Rica, especialmente a partir de los años 30 (ver 121-65). Valiéndose del estudio de Ovares et alii (1993), escribe en relación con la narrativa de Max Jiménez y Carlos Salazar Herrera lo siguiente: "En estos textos [...] se introducen innovaciones importantes en la imagen de lo nacional. Aparece una mayor complejidad en las relaciones entre el escritor, el lenguaje, la realidad representada, y el virtual lector. Es cada vez más fuerte la reflexión del escritor sobre el lenguaje, que empieza a perder su función directamente referencial y su inocencia: la escritura se hace consciente $-\mathrm{y}$ hace consciente al lector- del carácter convencional del lenguaje literario; las imágenes pierden su transparencia, ya no tienen como función única el simular ser un reflejo especular de una realidad exterior al lenguaje, y asumen otras funciones que ponen en evidencia su carácter convencional. Se resquebraja la imagen idílica del país vergel [...] Estos cuentos mezclan de manera inédita elementos del realismo costumbrista con procedimientos de subjetivización de lo real, para lograr un efecto 'desrealizador': las imágenes cobran autonomía y el paisaje nacional se integra bajo una voluntad estetizante" (156-7). Como intento demostrar en este ensayo, estas tendencias se articulan de una manera aún más marcada y radical en la novela de Yolanda Oreamuno.

\section{Bibliografía}

Arce Arce, Marta Eugenia. 1980. "Inner and Outer World in To the Lighthouse and La ruta de su evasión". Tesis de Licenciatura en Literatura Inglesa: Universidad de Costa Rica.

Bajtín, Mijail. 1986. Problemas literarios y estéticos. La Habana: Editorial Arte y Literatura.

Barbas-Rhoden, Laura. 2003. Writing Women in Central America. Gender and the Fictionalization of History. Athens: Ohio University Press.

Bonilla, Abelardo. 1957. Historia de la literatura costarricense. San José: Editorial de la Universidad (3 ${ }^{\text {a }}$ ed.: San José 1984: Editorial Studium).

1961. Historia y antología de la literatura costarricense. San José: Imprenta Trejos Hermanos, 2 tomos.

Bronfen, Elisabeth. 1986. Der literarische Raum: Eine Untersuchung am Beispiel von Dorothy M. Richardsons Romanzyklus Pilgrimage. Tübingen: Max Niemeyer Verlag.

Cortés, María Lourdes. 1996. "Palabras de mujer. Una mirada hacia la narrativa costarricense". Urogallo. Revista Literaria y Cultural. Julio: 27-30.

Chase, Alfonso. 1975. Narrativa contemporánea de Costa Rica. Estudio introductorio y notas. San José: Ministerio de Cultura, Juventud y Deportes. 
2006. "Yolanda Oreamuno: contra el olvido". Tribuna Democrática. 3 de julio. http:// www.tribunademocratica.com /2006/07/yolanda_oreamuno_contra_el_olvido.html. Consulta: 25 de octubre 2007.

Ette, Ottmar. 2001. Literatur in Bewegung: Raum und Dynamik grenzüberschreitenden Schreibens in Europa und Amerika. Weilerswist: Velbrück Wisenschaft.

2003. Literature on the Move. Amsterdam: New York: Rodopi.

Garro Jiménez, Haydeé. 1977. "Isotopía de la mujer alienada en La ruta de su evasión de Yolanda Oreamuno". Monografía para optar al grado de Licenciada en Filosofía y Letras. San José: Universidad de Costa Rica.

Grinberg Pla, Valeria y Werner Mackenbach. 2006. "Banana novel revis(it)ed: etnia, género y espacio en la novela bananera centroamericana. El caso de Mamita Yunai". Iberoamericana. América Latina - España - Portugal. 23: 161-78.

Hidalgo Jiménez, Marcela. 2006. "Sobre centros: 'El ambiente tico y los mitos tropicales' de Yolanda Oreamuno". Istmo. Revista virtual de estudios literarios y culturales centroamericanos. 12 (enero-junio). http://www.denison.edu/istmo.

Macaya, Emilia. 1997. Espíritu en carne altiva. San José: Editorial de la Universidad de Costa Rica.

Mahlendorff, Andrea. 2000. Literarische Geographie Lateinamerikas: Zur Entwicklung des Raumbewußtseins in der lateinamerikanischen Literatur. Berlin: Edition Tranvía, Walter Frey.

Naranjo Coto, Carmen. 1971. "El mundo incomunicado de La ruta de su evasión". Artes y Letras (Ministerio de Educación Pública de Costa Rica). 2 (14).

Oreamuno, Yolanda. 1961. A lo largo del corto camino. San José: Editorial Costa Rica.

1949. La ruta de su evasión. San José: EDUCA (5ª ed., 1994).

Ovares, Flora et alii. 1993. La casa paterna: Escritura y nación en Costa Rica. San José: Editorial de la Universidad de Costa Rica.

Quesada Soto, Álvaro. 1998. Uno y los otro: Identidad y literatura en Costa Rica 1890-1940. San José: Editorial de la Universidad de Costa Rica.

Picado Gómez, Manuel. 1979. "La ruta de su evasión” de Yolanda Oreamuno. Deslinde metodológico y contribución al estudio de la literatura costarricense. San José: Editorial de la Universidad de Costa Rica. 
Robles Mohs, Yvonne. 1988. "Un nuevo modo de narrar: La ruta de su evasión de Yolanda Oreamuno". Káñina. Revista de Artes y Letras de la Universidad de Costa Rica. 12 (1): 49-53.

Rojas, Margarita y Flora Ovares. 1995. 100 años de literatura costarricense. San José: Ediciones FARBEN.

Vallbona, Rima de. 1975. Yolanda Oreamuno presentada por Rima de Vallbona. San José: Ministerio de Cultura, Juventud y Deportes.

1995. La narrativa de Yolanda Oreamuno. San José: Editorial Costa Rica.

2006. Yolanda Oreamuno. San José: EUNED.

Ulloa Zamora, Alfonso. 1962. "La mujer en la literatura costarricense”. Brecha. 5 (enero): 7-9.

Urbano, Victoria. 1968. Una escritora costarricense: Yolanda Oreamuno. Ensayo crítico. Madrid: Ediciones Castilla de Oro. 